\section{CONSERVATIVE MANAGEMENT OF PLACENTA INVADING INTO LEIOMYOMA}

Sir,

Leiomyoma uteri with pregnancy may lead to spontaneous abortion, preterm delivery, obstructed labor, or malpresentation. ${ }^{[1]}$ We report an unusual case of leiomyoma with pregnancy, resulting in preterm delivery, followed by retained placenta which was invading into the leiomyoma. Placenta was left inside and treated successfully with methotrexate.

A 25-year-old primigravida with 25-week pregnancy presented with complaints of pain abdomen off and on for 1 month and leaking per vaginum. Obstetrical examination revealed a 32 - week size uterus. The fetal parts were felt in the upper part of uterus, and a hard mass $(13 \times 10$ $\mathrm{cm}$ ) was found arising from the outer surface of lower uterine segment. The cervix was 5 to $6 \mathrm{~cm}$ dilated; the membranes were absent; and fibroid was felt arising from lower uterine segment, which was projecting into the uterine cavity. The presenting part was high up and not felt because of the fibroid. Ultrasonography revealed a 23-week single live fetus, reduced liquor; and a heterogeneous mass $(117 \times 85$ $\mathrm{mm}$ ) suggestive of fibroid anteriorly in uterus, extending in the lower segment. She delivered a fresh stillborn baby weighing $750 \mathrm{~g}$. The placenta did not separate; therefore, manual removal of placenta was attempted. However, it was found to be embedded into the fibroid without any plane of cleavage. Since the patient was not bleeding, the decision to leave the placenta inside was taken in consultation with her family, and the cord was cut as high as possible. The MRI scan on the $15^{\text {th }}$ postpartum day revealed enlarged uterus with well-marginated heterogeneous mass $(12.3 \times 10.5 \times 12 \mathrm{~cm})$ without any interface with the endometrial stripe in posterior-inferior part and with thinning of anterior myometrium [Figure 1]. The patient had profuse vaginal discharge mixed with bits of tissue and membranes, histology of which revealed autolyzed tissue. Methotrexate was given in a dose of $50 \mathrm{mg}$ intramuscularly on 7,14 and 21 postpartum days. On the $21^{\text {st }}$ postpartum day, the patient passed fleshy mass, which histopathologically revealed autolysed fibroid with decidual tissue. The patient had fever off and on till the $37^{\text {th }}$ postpartum day; thereafter, she remained afebrile and was discharged on the $53^{\text {rd }}$ day. No mass was palpable per abdomen at the 6-week follow-up, and the patient resumed normal menstrual period. 


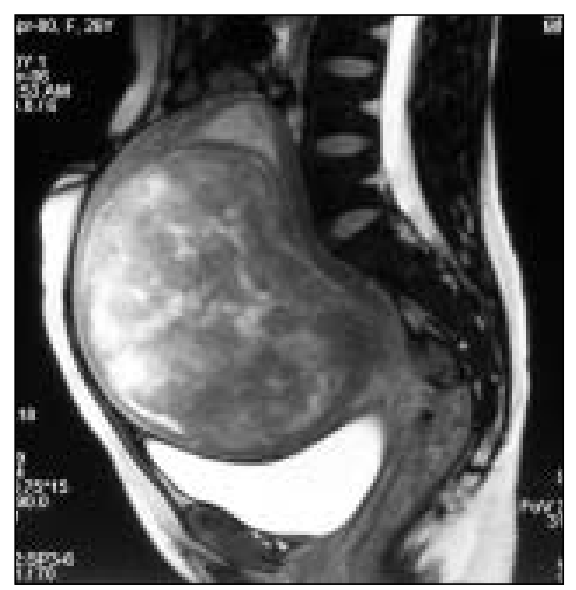

Figure 1: MRI, sagittal section, showing big anterior wall fibroid displacing the uterine cavity postero-superiorly. Bladder is seen as a white shadow antero-inferior to the fibroid

Cases have been reported where placenta was retained due to myoma requiring manual removal. ${ }^{[2]}$ Also, cases of placenta accrete where placenta was left inside and the patient managed with injection methotrexate have been reported. ${ }^{[3]}$

Here, we have reported a case where manual removal of placenta failed because placenta happened to invade into the myoma. The placenta was left inside, and the patient was given 3 doses of injection methotrexate. No such case has been reported in the literature. Advantage of placenta being left inside is preventing heavy postpartum hemorrhage. Possible disadvantage of this approach is risk of sepsis.

\section{KRISHNA AGARWAL, CHITRA RAGHUNANDAN ${ }^{1}$}

Department of Obstetrics and Gynecology, Maulana

Azad Medical College, New Delhi, 'Department of Obstetrics and Gynecology, Lady Harding Medical College, New Delhi, India

Correspondence: Dr. Krishna Agarwal 179, Type 3 Quarters, Ayurvigyan Nagar, Near Ansal Plaza, New Delhi, India. E-mail: drkrishna_agarwal@yahoo.com

\section{REFERENCES}

1. Buttram VC Jr, Reiter RC. Uterine leiomyomata: Etiology, symptomatology and management. Fertil Steril 1981;36:433-45.

2. Gleeson NC, Onwude JL. Uterine leiomyoma causing retained placenta. $\mathrm{Br} \mathrm{J}$ Clin Pract 1990;44:689-90.

3. Nijman RG, Mantingh A, Aarnoudse JG. Persistent retained placenta percreta: Methotrexate treatment and Doppler flow characteristics. BJOG 2002;109:587-8. 